\title{
Modelling Knowledge for a Natural Language
}

\section{Understanding System}

\author{
Gudrun Klose, Thomas Pirlein \\ IBM Germany \\ Scientific Center \\ Institute for Knowledge Based Systems \\ P.O.Box 800880 \\ D-7000 Stuttgart 80 \\ Email: KLOSE@DS0LILOG, PIRLEIN@DS0LILOG
}

\begin{abstract}
In the field of knowledge based systems for natural language processing, one of the most challenging aims is to use parts of an existing knowledge base for different domains and/or different tasks. We support the point that this problem can only be solved by using adequate metainformation about the content and structuring principles of the representational systems concerned. One of the prerequisites in this respect is the transparency of modelling decisions.

After a short introduction to onr scenario, we will propose general dimensions for cliaraclerizing knowledge in knowledge based systems. These dimensions will be differentialed according lo linguistic levels of investigation in order to deduce structuring principles for the modelling process. The resulting criteria will be evaluated in a detailed exainple taken from our prototypical implementation.

We hope to contribute some promising steps towards a methodology of knowledge engineering with natural language and common sense orientation.
\end{abstract}

\section{Introduction}

In the following, we waut to sketch first results of knowledge engineering research which was undertaken for the LILOG project (Linguistic and logic methods). LILOG develops concepts for naturn language systems for text understanding. Major results are available in a prototype system LEU $/ 2^{1}$ (LILOG Experimentier- Ungebung)

In order to reduce the complexity of the system, it has to be decomposed into modules.

\footnotetext{
'Leu/2 is being developped at IBM Germany in coopern. tion with some unirersity partners, and is fully implemented in Prolog under AIX. The knowledge base for the domain un. der investigation consists of aboul 600 concept defunitions, among these ome 100 belonging to the upper atructure. The number of attributes for ench of these concepts nver. ages around 20. At this lime the number of nxioms for our domain is approximntely 300.

2"LILOG Experimental Environment"
}

Our nppronch embodies modules oriented towards levels of linguistic investigntion like morphology, syntax and semnntics. In addition the modules differentinte between analysis and the generntion processes. In the idenl case, all processes nind modules will be supported by comunonsense knowledge.

A crucial problem in this context is the construction of an adequate background knowledge base. The need for a methodology is obvious. First steps have been made in expert system resenrch, where both domain and task are for the most part clearly specifiable. This does not hold for systems witl naturnl language - nnd conumon sense orientation. In what follows, we will outline the knowledge entginecring appronch in LILOG along three dimensions.

\section{Task:}

Domnin and téxts were selected in order to cover a wide variety of lingnistic phenomenn to be handled by the linguistic parts of the system (i.e. parsing and generating components). In order to prove the approprinte understanding of the texts, the architecture was dessigned n.o. as a question/answer system. Hence, we get the additionnl tnsk to generate langunge.

\section{Domain:}

For LEU/2, the domain was restricted to travel guide information about the city center of Düsseldorf. As a first step, a set of written data was obtained by travel guides, supplemented by travel agencies and a local inspection of Düsseldorf city ceniter.

The set of different entities was to meet the following conditions: it should be large ellough for a relevant size of the knowledge base, interconnected enough to allow for interesting inferences but at the snine time small enough for being handled within a prototypical implementation.

We decided to work with a couple of short texts (frequently found in travel guides), which describe 
particular sightseeing items, nnd a one page narrative text about a group of people on a prototypical sightseeing tour. In the next step, the chosen texts were classified according to linguistic criterin and analyzed for their propositional contents.

\section{Granularity:}

In order to obtain a first hint at the variety of text understanding tasks which LEU/2 was intended to deal with, native spenkers were asked to formulate questions and to provide acceptable answers concerning the contents of the texts.

The selection of items and the wny these native speakers talked nbout them, served as guideline to determine an npproprinte grnmularity of the knowledge base.

The overall performance of the system is determined by the interaction of its components. Due to the modular approach, the relevant subtasks of the knowledge base had to be separated from those of the lexical, syntactic, semantic analysis compo. nents and the generation module. As n result of this prelinumary investigntion, three dimensions of knowledge turned out to be crucinl to the modelling process.

\section{Dimensions of Knowledge}

We will discuss knowledge from two different perspectives. On the one hand we have those conditions which lead to qualitative requirements concerning the contents of the knowledge base. The other perspective concerns aspects induced by formal devices, i.e. the kuowledge representation fornualism used.

\subsection{Qualitative Dimensions}

If you consider knowledge representation as a special cnse of model theory, you will get $n$ hint of how to proceed. As to the breadth of the model, the first dimension at issue, this menns:

The job of the representing world is to reflect some aspects of the represented world in some fashion.[Palmer, 1978]

As regarding granularily, the second dimension, a model reflects only a subset of the charncteristics of the entities it represents. This, in turn, determines the depth of the model.

$\Lambda$ third dimension is given by the complexity of the task the model is intended to cover.

All three dimensions nre shown in picture 1.

Some of the consequences for the model in LILOG following from this view of knowledge representation nre described below.

\subsection{Formal Devices of Representa- tion}

In the field of logic bnsed formalisms for coding background knowledge in unturnl langunge process-

\section{Brendth of the doinnin}

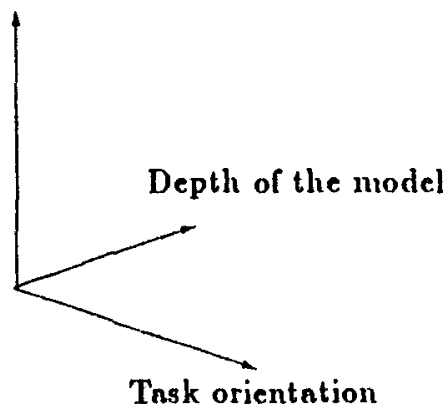

Figure 1: Qualitative dimensions of knowledge

ing systems, there is some controversy on the design and use of formal constructs. Topics in this debate are the function of axioms compnred to recent expert system technology, the function of structured concept hiernrchies [Monnrch nud Nirenburg, 1987], the quality and number of ndditional attributes (roles in KL-ONE like systems) or syntactic validation criteria [Horncek, 1989]. Our approach aims nt firiding useful selectional criterin for different expressive menns of the formalism $\mathrm{L}_{\mathrm{L} \text { ILOG }}$ in order to bridge the nctunl gap between problem driven and technology driven ${ }^{3}$ rescarch.

We can make use of two kinds of formal constructs:

- A frame-description language similar to KL ONE (cf. e.g. [Brnclumnn nud Sclimolze, 1985]), which serves to represent the terminology of the domnin by means of

- sort expressions for clnsses of entities, orgnnized hierarchically as sets nnd subsets (i.e. the logicnl subsumption relation), and

- two place predicates nud functions (i.e. features and roles), attached to specific sorts and constituting functional and relational connections between sorts, and

- axiouns of first order predicnte logic, expressing inferential dependencies between domain terms in form of the axiomntic semnntics for those terms.

So the formalism nsed here is comparable to e.g. KRYPTON (s.e.g. [Brachman et al., 1985]).

In the following, we will discuss the qualitative dimensions of knowledge in more detnil. We will focus the qualitative criterin by differentinting them according to our scenario.

\footnotetext{
See [Lohnert, 1988] for that distinction.

"For a detailed description of the formalism LLILOG see [Plotat and ron Luck, 1989]
} 


\section{Criteria for Struct uring the Ontology}

\subsection{Demands Resulting from the Task}

As mentioned above, the task of our system is to simulate text understanding. This requires a transfer of insights from linguistic resenrch into knowledge engineering. In the idenl case, structures of the model will be strongly influenced by natural language analyses.

Linguistic knowledge is relevnut in various respects:

- Word orientation, for example, implies close interrelationships with research on lexical knowledge: nffiliated generic terms, discriminating features, idiosyncratic aspects of use, etc. However, you may run into difficulties by relating syntactic categorics (like word clnsses) with conceptual structures. So thematic roles cannot be directly transformed into ontological roles as a part of the background knowledge. In the sentence

The bus took the participants of the conference to the city center. ${ }^{3}$

the 'bus' is an ngent of an event from the syntactic point of view and at the same time conceptunlized ns instrument (and not ngent) of an event in an ontologicnl sense.

- Sentence oriented linguistic investigation implies the reconstruction of knowledge on the sentence level, ns opposed to the menning of single words or of textunl structures. As an illustration night serve temporal information nbout the progress of nctions or situntions. Theoreticnl work in this field was initinted e.g. by Z. Vendler [Vendler, 1967) with his nunlysis of verbs nnd times. His differentintion of states, activities, accom. plishments nnd achievements hns been established as a well known clnssification of verbs. One important criterion for this distinction is the goal-orientedness of the concermed verbs: states and activities are by definition not goal-oriented, wherens nccomplishments and achievements nre goal-oriented in n temporally extended or punctunl way, respectively.

The nspect of gonl-orientedness turned out to be central in our domain, e.g. ns to directional verbs of movement. The sentence

The tourists took the bus to the Rhine and went for boat trip."

\footnotetext{
The Gexinnn veruion of the sentence is part of the text corpus of $\mathrm{LEU} / 2$ : "Der Bub brachte die Teilneluner der Konferenn in die Innentad!".

"Die Touriaten nolumen den Bus bis mun Rhein und machten einen Bootanusflug."
}

allows to infer by default that the tourists reached their gonl (the Rhine), becnuse the location of the following event (the boat trip) is the same as the arrival point of the bus ride. By introducing gon-orienteduess ns a part of the definition of events, it will hence be possible to give an affirmative nnswer to the question

Were the tourists at the Rhine?

- Moreover, a text necessarily involves discourse oriented informntion. Text understanding phenomenn like nnnphora resolution can only be nccounted by nccessing bnckground knowledge concerning interconceptual relation.

The tourists went for a boat trip. They took the seats on the sundeck.

In order to capture the meaning of these sentences, three steps have to be inferred: $A$ bont trip is usunlly undertaken with $n$ bont; a boat often has a snndeck; and a sundeck mostly offers seats.

\subsection{Demands Resulting from the Domain}

In the LEU/ 2 context, we have to deal with the comprehensive task of text understanding and a relatively narrow domain. Consequently, the general problem of conceptualizntion is linited by a restricted number of entities relevant to our field. Modelling these entities includes both the selection of concepts which appear in the donain, nnd the plausible combination and sumuning of recurrent concepts. The plausibility of modelling decisions in this sense can be judged from nu engineering point of view in terms of optimizing search space (system performnnce) and from a philosophical point of view in terms of the principle of economy of the ontology.

The concepts restauration, CONSTRUCTION and RBNOVATION may serve as an illustration taken from our domain. As they share sinular aspects and inferences, we decided to introduce the supersort MODIFICATION (see section 4).

\subsection{Granularity: Depth of Mod- elling and Inferencing}

In the third qualitntive dimension of knowledge we have to face the problem of delimitating the depth of the model in order to reduce complexity. As it is not possible to give

\footnotetext{
"Waren die Touristen nm Rhein?"

- The German version of tho sontence is part of the text corpus of LEU/2, "Dis Touristen machten einen Booteausfug. Sio nnhmen dị PIñtse nuf dem Sonnendeck ein".
} 
an exhaustive system of categories ${ }^{9}$, it seems legitimnte to determine primitive concepts dependent on the chosen tnsk nud domain. In addition, selectionnl criterin for clusters of inferences have to be determined. (Sec example in section 4). As a possibility of measuring the depth of a model, Hayes ([Hayes, 1979]) proposed a ratio of axioms per concept.

Aside from mensuring the expression of dimensions of knowledge by merus of quantitative data, it is important to consider qualitative dependencies between the depth and task of the model on the one hand and between the depth and domain on the other.

\section{Depth in relation to the task}

Within the task of text understanding; some requirements of representation nre e.g. gonl orientation, culmination, causal connections, intention, etc. [Trabasso nnd Sperry, 1985]. In all these cases the cloosen gramularity has strong impact upon the resolution of interrelations in the texts. ${ }^{10}$

\section{Depth in relation to the domain}

This connection can be illustrated by the following exmmple: $A$ typical event of our domain is RESTAURATION. In our scenario, touristic aspects like the architect (agent), the time and the object concerned (e.g., the facade) will be of crucinl importance. Gjven a different scenario like the protection of historical monuments, we would have to face an interest in considerably more details, requiring the clioice of $n$ deeper grnnularity.

\section{Design of the Knowl- edge Base}

In this section, we first want to give a brief survey of the ontology. $\Lambda$ fter that, we will take up the sorts nud regulnrities mentioned so far and present a structured exemplary model formalized in $\mathrm{L}_{\text {LILOG }}$.

Sort expressions are used to represent the categories of our domnin model. The upper structure of the resulting ontology portrays some generalized schemes of organization of relative domain-independence. When descending the model townds the lower structure, the categories are defined much closer to the word level and therefore domnin-specific in the sense of explicit text knowledge.

As alrendy mentioned, we want to simulate understanding of basically two different types of

\footnotetext{
- See for exnmple [Tamas, 1986, p. 509]

in For a more detniled discussion, ee [Pirlein, 1990].

11 This differentiation befween upper and lower structure of the model is introduced by [Mnmu et nl., 1985].
}

texts, i.e. short texts describing single sightsceing items and narrative texts denling with sequences of events. This lends us to the requirement of both an object-oriented and nn event-oriented part of the conceptual hierarcliy.

Consequently, one of our basic design decisions is due to J. Hobbs (cf. [Hobbs et nl., 1987]) and results in a reification of predicates. So in our model all events, stntes etc. linve concept status on their own.

This technique enables us to model the case frnmes for verbs in an nunlogicnl mnuner to the lexical entries of the annlyzing component as well as to incorporate the structures for events etc. within the cntegories alike the definitions for objects. ${ }^{12}$. It makes sense to think about objects ns well as nbout events in terms of their spatial and temporal environment, although these knowleidge specifications will obviously be quite different.

An exnmple taken from the event cluster may serve as an illustration of severnl consequences of the criteria mentioned above. As to the breadth of the model, the relevnnce of the event part of the ontology nppears intuitively plausible with respect to our domain, namely a scenario of cities, with modifying events. We have to deal with sights of the city like facades of important.bnildings, and the events of modification related to them slow a considerable resemblance of important features of meaning - although the verbs are no renl synonyms in the linguistic sense.

Figure 2 shows a screen dump with the relevant part of the concept hierarcly. The picture illustrates the effect of bundling that the introduction of adequate superconcepts has, and which allows for structured inferencing in terms of system efficiency. In this part of our concept hiernachy the bonrderline between Upper Structure nud Lower Structure is clearly identifiable. When descending the hiernrchy, the sort KONSTRUKTIVSIT fnus out into several domnin-dependent subsorts.

The figure is followed by the respective sort expressions written in the $\mathrm{L}_{\mathrm{LILOG}}$ list structure(the sort KONSTRUKTIVSIT in the figure corresponds to CONSTRUCTION in the English list of sort expressions), expanded by roles and features which do not nppear in the graphic representation. It should be noted here that a third kind of information is onitted even in the list notntion. More general roles and features (like e.g. ngent, time and so on) are inherited by superconcepts and not visible in neither presentation. (The short line in the upper left corner of some concept boxes indicate the existence of additional hidden superconcepts.)

\footnotetext{
i2 A similiar teclunique you can find e.g. in [Mann et al., 1985].
} 


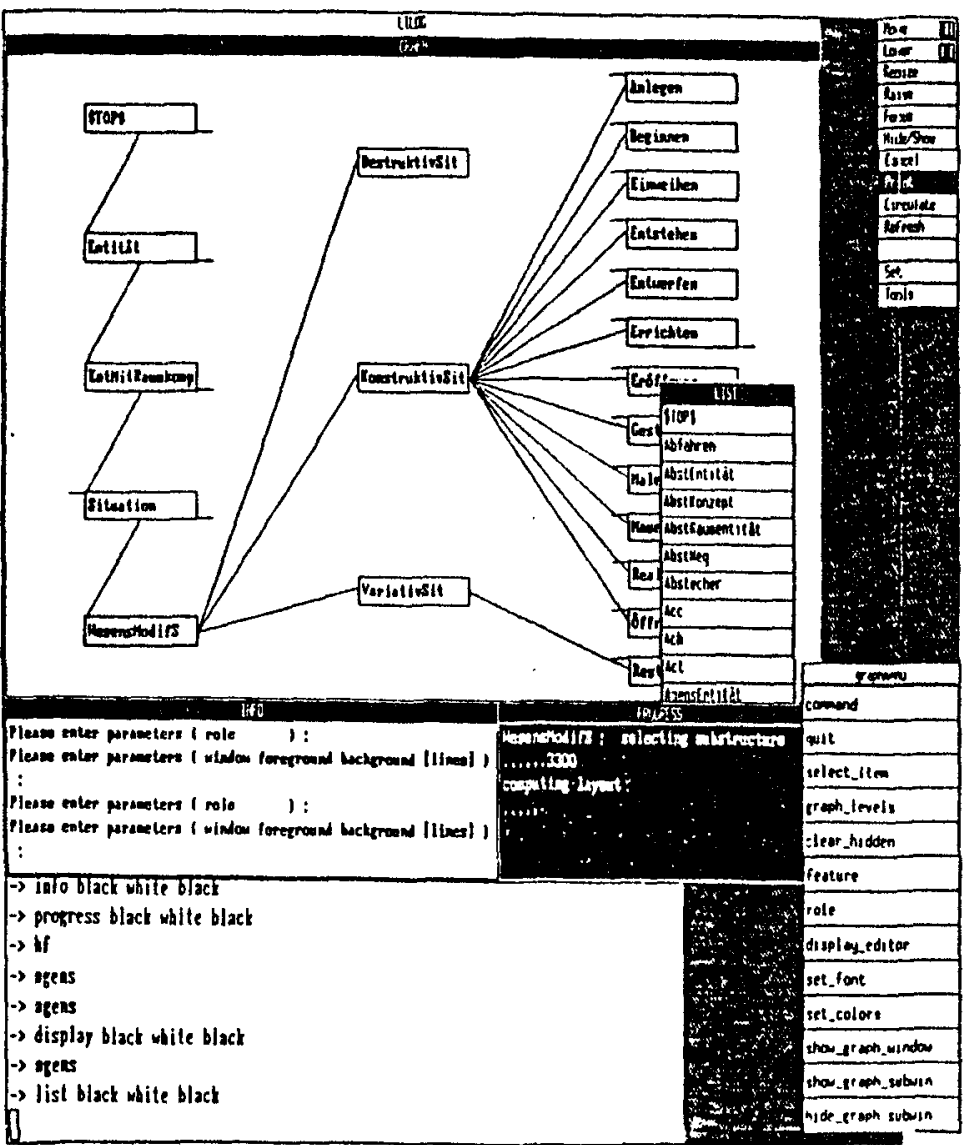

Figure 2: Implementation of the 'modificntion'event

The definition of the relevant event concepts in $L_{\text {LIno }}$ is followed by an axion which transfers information about the time of a construction event to the beginning of lifetime of the concerned object. This kind of structured modelling allows to dispense with writing sinilar axioms for a number of resembling events.

In order to demonstrate task orjentation, it would be necessary to consider a broader part of the ontology, becnuse aspects like intention, causality or culmination have. been nodelled separately. In addition, one would have to take a closer look at the ensemble of connected conponents in the system. The limitation of the depth of the model can be seen from the fact that the event concepts discussed do not have more differentinted subconcepts and, of course, from the fact that not all possible roles and features have been integrated into the model. In a scenario "protection of historical monuments", for example, the instruments of renovation might be central and would induce a partly different granularity in the model.

\section{Definition in I/Lung:}

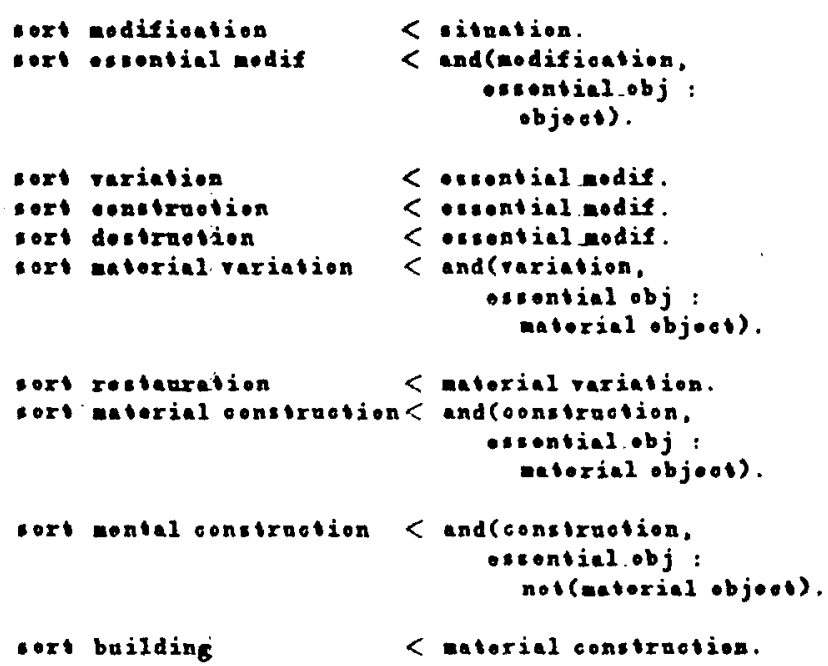

The twofold modelling of PHYSICAL and MENTAL CONSTRUCTION is e.g. necessary to distinguish ideas developped by an nrchitect from the realization of the building. ${ }^{13}$

For constructive events one can define the following regularity (nxion):

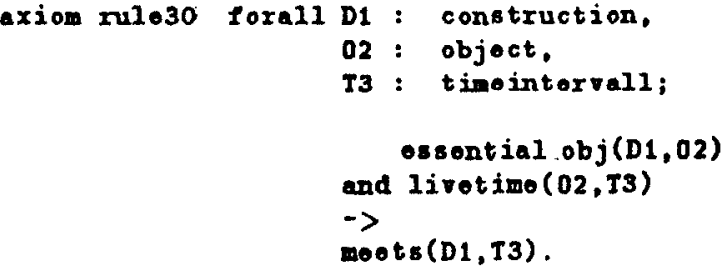

The relation moots is one expression of our nxiomatization of Allen's time interval logic [Allen, 1983) in $\mathrm{L}_{\text {LILOG . Rul.30 exemplifies }}$ a transformation rule between the clusters of events and objects, respectively.

Our task setting implies certain ways of interaction between Knowledge Engineering and the generation component. If you want to obtain flexibility for the generation component with respect to the possible diversity of an$s$ wers, information should be available in cases of object centered questions

("What do you know about object xy ...")

as well as in comparable event oriented requests

("What happened after ...").

\footnotetext{
12 For reasone of clarity we renounced on thowing all reapective eupereorte.
} 


\section{Conclusion}

One of the most discussed topics in the field of text understanding is the separation between semantic knowledge on the one hand and common sense knowledge or world knowledge on the other. During the conception and implementation of the modules in our prototype, this discussion was reflected by $n$ considerable fexibility in the division of functions between semantic nualysis and inferential processes.

During the integration, descriptive parts of linguistic theories hand to be completed with procedurnl or functional aspects. Typical inisfits appenred each time it wns clear what should be expressed within certnin modules (like norphology or syntax), but it was unclenr how to proceed from one module to the next. In the ideal case, this allowed for conclusions on incompntibilities between the levels of linguistic nnalysis corresponding to the respective modules.

One of these phenomenn is the identification of ndjectival pnssive constructions versus regular verb:

The museum will be opened at 11 a.m. ${ }^{14}$.

The nuseum is open from $\theta$ to $15^{16}$.

According to Vendler's classification; open should be cntegorized as nu event in the first sentence and, combined with to be in the second case, as a state. The integration of the modules showed that none of the system components was able to deliver this differentiation - in this case, the reason was the incompatibility between unsorted unificntion grammars and the necessity to overwrite defanlt values.

In the field of Knowledge Engincering, the question how to make contents of one knowledge base avnilnble to a second one (normally with quite nnother kind of task setting) has been receiving growing attention. One of the most interesting parts of this problem consists in the interrelntionship between common sense - and domain specific knowledge. We hope to contribute some important steps towards handling this problem by making explicit a number of common sestse oriented modelling decisions within the LII,OG context. It is obvious, though, that both bnckground knowledge for naturnl language processing and the adequate implementation of metainformation for knowledge base contents will be nu ongoing affair for the next yenrs.

Acknowledgement: We thank Bart Geurts, Tibor Kiss, Ewald Lang, Kai von Luck and Mar. tin Mezger for useful idcas and stimulating discussions.

\section{References}

[Allen, 1983] Jnmes F. Allen. Maintaining knowledge about ternporal intervals. Communicatione of the $A C M, 26(11): 832-843$, November 1983.

[Brachmnn and Schmolse, 1985] Ronald J. Brnchman and James G. Schmolue. An overview of the KLONE knowledge represent ntion system. 9(2):171216, April 1986.

[Brachman ot al., 1985] Ronald J. Brachunnn, Victoria Pigman Gilbert, and Ilector J. Levesque. An essential hybrid rensoning eyetem: knowledge and njmbol level nccounts in KRYPTON. pages 532539, August 1985.

[Hayes, 1979] Pnlrick J. Hayes, The nnive physics manifento. In D. Michie, editor, Expert Syotemo in the Microelectronic Age, Edinburgh Unir. Prest, 1979.

[Hobbs of al., 1987] Jerry R. Hobbs, William Croft, and Todd Daries. Commonsense metnphysics and lexical semnntics. Compulational Linguivtice, 13(3-4):241-250, Angust 1987.

[Horacek, 1989] Helmut Horacek. Towarde principles of ontology. In D. Metsing, editor, Proc. GWAI 89. pages 323-330, Springer, Berlin, Germany, 1989.

[Lehnert, 1988] W.G. Lehnert. Knowledge based nntural language understanding. In $\mathbf{H}$. Strobe, editor, Bmploring Artificial Intelligence, pages 83131, Morgan Kaufmann, San Mnleo, 1988.

[Mnnn of al., 1986] William C. Mann, Yigal Arens, Christian M. 1. M. Matthiessen, Shari Naberschnig, and Norman K. Sondlueimer. Janus ab. straction structure-draft 2. Draft pnper, Univerity of Southern Californin, Information Science Institute, Mnrinn del Rey, Cnl., October 1985.

[Monarch and Nirenburg, 1987] 1. Monnrch and S. Nirenburg. The role of ontology for knowledgebased eystems. In B. Gaines J. Boose, T, Ad. dis, edilor, Proc. EKAW-87, Reading University, Resding, Mnas., 1987.

[Pnlmer, 1978] Steplien E. Palmer. Fuidnmental aspect. of cognitive represenlntion. In Elennor Rosch and Barbarn B. Lloyd, editors, Cognition and Categorieation, Lnw rence Erlbnum As. socintes, Hilladnle, New Jersey, 1978.

[Pirlein, 1990] Thomns Pirlein. Rekonotruktion von Hintergrundwisen für ein wissenobarierteo leztveratehendeo Syotem. IBM Deutschinnd GmbH, September 1990.

[Pletal and von Luck, 1989] Udo Pletnt and Kai von Luck. Knowledge Representation in LILOG. In Karl-Hans Bläsius, Uli Hedistück, and Claus Rollinger, editors, Sorts and Types in Artificial Intelligence, 1989.

[Tnmas, 1986] G. Tamna. The Logic of Categorien. W. H. Freemnn and Company, Stultgart, 1986.

[Trabasso and Sperry, 1985] T. Trabasso and L.L. Sperry. Causal relatedness and importance of story orents. Journal of Memory and Language, (0):686-611, 241988.

[Vendlex, 1967] Zeno Vendler. Linguiotico in Philosophy. Cornell Univereity Press, Ithaen, N. Y., 1967.

\footnotetext{
14 "Das Muscum wird um 11 Uhr geöftnet"

16 "Dan Museum ist von 9 bie 15 Uhr geöfnet"
} 